
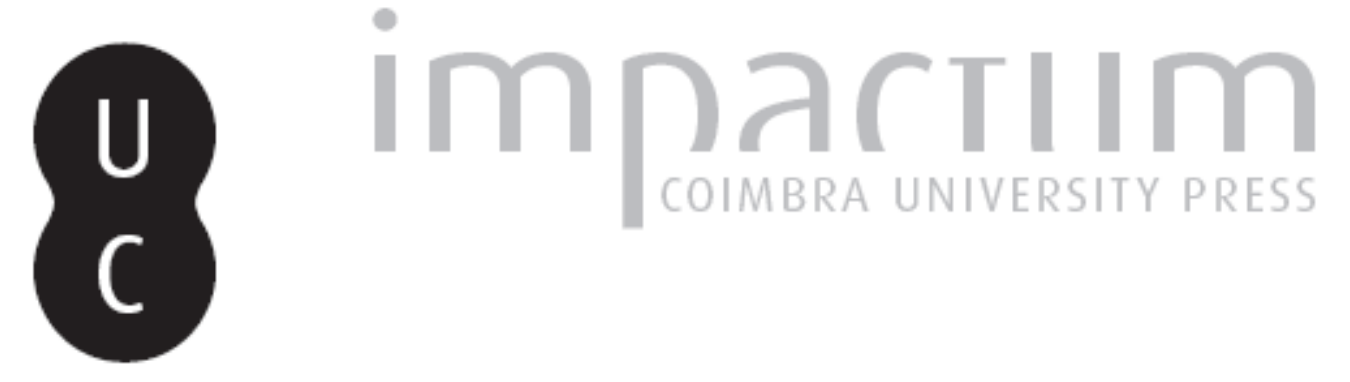

\title{
Fornos de ânforas do Monte da Enchurrasqueira e do Vale da Cepa: notícia preliminar
}

\author{
Autor(es): $\quad$ Diogo, A. M. Dias
}

Publicado por: Imprensa da Universidade de Coimbra

URL persistente:

URI:http://hdl.handle.net/10316.2/45698

DOI:

DOI:https://dx.doi.org/10.14195/1647-8657_22_3

Accessed : $\quad$ 26-Apr-2023 10:32:32

A navegação consulta e descarregamento dos títulos inseridos nas Bibliotecas Digitais UC Digitalis, UC Pombalina e UC Impactum, pressupõem a aceitação plena e sem reservas dos Termos e Condições de Uso destas Bibliotecas Digitais, disponíveis em https://digitalis.uc.pt/pt-pt/termos.

Conforme exposto nos referidos Termos e Condições de Uso, o descarregamento de títulos de acesso restrito requer uma licença válida de autorização devendo o utilizador aceder ao(s) documento(s) a partir de um endereço de IP da instituição detentora da supramencionada licença.

Ao utilizador é apenas permitido o descarregamento para uso pessoal, pelo que o emprego do(s) título(s) descarregado(s) para outro fim, designadamente comercial, carece de autorização do respetivo autor ou editor da obra.

Na medida em que todas as obras da UC Digitalis se encontram protegidas pelo Código do Direito de Autor e Direitos Conexos e demais legislação aplicável, toda a cópia, parcial ou total, deste documento, nos casos em que é legalmente admitida, deverá conter ou fazer-se acompanhar por este aviso.

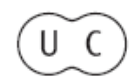


FACULDADE DE LETRAS

INSTITUTO DE ARQUEOLOGIA

\section{CONIMBRIGA}

VOLUMEXXII

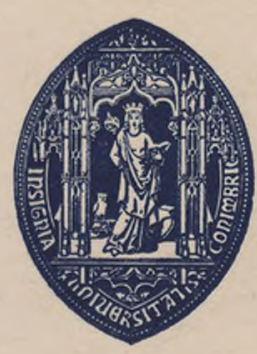

UNIVERSIDADE DE COIMBRA

1983 


\section{A. M. Dias Diogo}

Assistente da Faculdade de Ciências Sociais e Humanas da Universidade Nova de Lisboa

\section{FORNOS DE ÂNFORAS DO MONTE DA ENCHURRASQUEIRA E DO VALE DA CEPA — NOTÍCIA PRELIMINAR}

Conímbriga, X X I I (1983), p. 209-215

RESUmo : 0 autor dá breve notícia de mais dois centros produtores de cerâmica no curso inferior do Sado. Para além de ânforas de tipo Dressel 14 e Almagro 51C, estes fornos produziram ainda outras formas de cerâmica comum associáveis ao fabrico e transporte de garum.

RÉSUMÉ : Deux fours d'amphores romaines sont ajoutés à la liste de ceux déjà connus dans la basse vallée du Sado. Céramique commune destinée à la préparation et transport du garum a été fabriquée dans ces fours, en même temps que des amphores Dressel 14 et Almagro $51 \mathrm{C}$. 
(Página deixada propositadamente em branco) 


\section{FORNOS DE ÂNFORAS DO MONTE DA ENCHURRASQUEIRA E DO VALE DA CEPA NOTÍCIA PRELIMINAR}

\section{I - Monte da Enchurrasqueira}

Estão situados a cerca de $100 \mathrm{~m}$ para $\mathrm{SW}$ do $\mathrm{km} 71$ do caminho de ferro do Vale do Sado (coordenadas hectométricas: 161.0 N, 162.0 E na Carta Militar 1:25.000, folha n. ${ }^{\circ}$ 467). Estes fornos são conhecidos desde 1896, altura em que Joaquim Correia Baptista escreveu em $O$ Archeologo Português: «Outro tanto sucederá no sítio da Xeroqueira, a cinco kilómetros a jusante de Alcácer e ainda na mesma margem, onde se vêem muitos fragmentos de amphoras e tijolos. Parece que houve ahi, como na Barrosinha, vários fornos» ${ }^{(1)}$. $\mathrm{O}$ facto $\mathrm{de}$ as cartas Militar e do Instituto Geográfico e Cadastral terem grafado o topónimo na forma popular (Enchurrasqueira) $\left(^{2}\right)$ levou a que a sua localização se tenha entretanto perdido.

Os fragmentos de ânfora que publico pertencem ao tipo DRESSEL 14/Beltran iv e sáo provenientes de uma vala de escoamento de águas que corta um autêntico monte de cacos; além das ânforas foram ainda fabricados nestes fornos outros tipos de cerâmica comum. De destacar, como característico dos fornos da Enchurrasqueira, a ocacidade dos bicos fundeiros.

As pastas caracterizam-se pela tonalidade uniforme dentro de cada vaso e pelas fendas abundantes, que lhes dão um aspecto folheado. Os elementos não-plásticos são muito abundantes, predominando o quartzo esbranquiçado de tamanho inferior a $1 \mathrm{~mm}$.

( 9 «Salacia», pág. 7.

(2) No mapa publicado por Virgínia RaU em $A$ exploração..., ó topónimo vem grafado Charroqueira. 
As inclusões negras e os quartzos glandes, atingindo $4 \mathrm{~mm}$, sâo escassos. 0 tratamento da superfície das ânforas é feita com aguada e alisamento a trapo, o que as deixou de tonalidade mais escura do que a pasta e com os característicos enrugamentos em forma de estrela.

1. Fragmento de bico fundeiro, oco e terminando em botão. Relação entre as medidas de altura e largura 3:1 $(\mathbf{1 2 , 5 \times 4 , 2 )}$. Pasta de tonalidade vermelho-alaranjado, engobe um pouco mais escuro.

2. Fragmento de boca, parte do colo e das asas. Lábio de perfil triangular, muito ligeiramente perolado. Reentrância interior para encaixe do opérculo. Asa de secção irregularmente oval, com canelura vertical exterior. Diâmetro de boca: 10,6 cm. Pasta de tonalidade vermelho-amarelado, engobe vermelho-tijolo.

\section{II - Vale da Cepa}

Também situados na margem direita do rio Sado, encontram-se a cerca de $800 \mathrm{~m}$ para Este dos fornos da Enchurrasqueira (coordenadas hectométricas: 161.2 N, 162.9 E na Carta Militar 1:25.000, folha $\mathrm{n}{ }^{\circ}$ 467). Devo a sua localização ao Sr. Augusto dos Santos que durante cerca de trinta anos cultivou arroz nesta pequena leira de feitio triangular, limitada a sul pelo caminho de ferro e nos restantes lados pela vala de rega. Segundo o mesmo senhor, teria aparecido a estrutura de um forno circular, quando nos últimos anos da década de quarenta se construiu a vala de rega, cerca de cinco metros a norte do pequeno barranco de onde recolhi os presentes materiais.

Estes fornos contam-se entre os de produção mais variada da margem direita do curso inferior do Sado; para além das ânforas dressel 14/Beltran IV e almagro 51C, ambas com grande variedade de formas de bordo, produziu ainda cerâmica comum, muito provavelmente, utilizada também no fabrico e transporte de garum. Há ainda a destacar a grande micacidade das pastas do Vale da Cepa ${ }^{3}$ ) em comparação com

(3) Num próximo trabalho publicarei as análises laboratoriais das pastas, assim como outros fornos ainda inéditos. 
as da Enchurrasqueira e a existencia de uma marca esgrafitada, em forma de cruz, no bico fundeiro de dresser 14 (n. $\left.{ }^{\circ} 8\right)\left({ }^{4}\right)$.

As pastas caracterizam-se, na sua generalidade, por não terem cor uniforme, com cerne geralmente de tonalidade mais viva. O aspecto é esponjoso, com poucas fendas. Pequeníssimas calcites; quartzos abundantes e muito pequenos, na maioria leitosos. Escassos ocres vermelhos e inclusões negras. Micácia. Quanto ao engobe, ele varia muito das oresser 14 (de tonalidade clara e com a superfície externa muito áspera, com inúmeros pequenos quartzos) para as almagro $51 \mathrm{G}$ (de engobe escuro em superfície bem alisada).

3. Fragmento de boca e colo de pote. Vestígio de asa arrancando da sobreira do bordo. Estrangulamento interior, à maneira das ânforas, para encaixe da tampa. Deveria servir para o transporte de garum. Bordo tipo aba, de secção em ogiva. Colo oblíquo, para o exterior; ornamentado com duas caneluras. Diâmetro interno da boca: 9,6 cm. Pasta amarelo-alaranjada, com cerne extenso, laranja-avermelhado. Paredes bem alisadas, com engobe castanho-amarelado.

4. Fragmento de boca e colo de pequeno alguidar, ou almofariz. Bordo em forma de aba horizontal, larga, com reentrâncias nos lados superior e inferior para encaixe dos dedos. Copa sobre o hemisférico, decorada com pequeno ressalto e canelura angular. Diâmetro total da boca: $38 \mathrm{~cm}$. Pasta amarelo-alaranjada, cerne amarelo-acinzentado. Engobe de aguada, um pouco mais escuro do que a pasta. Superfície áspera com pequenas estrias horizontais.

5. Fragmento de bordo, parte do colo e asa de ânfora Dressel 14 Lábio de perfil triangular, de bordo liso e ligeiramente oblíquo, descaindo para o exterior. Reentrância interior para encaixe do opérculo bem vincada. Asa de secção irregularmente rectangular, com canelura vertical exterior. Diâmetro interior da boca: $13 \mathrm{~cm}$.

Pasta amarelo-alaranjada, cerne laranja-avermelhado. Engobe acastanhado, parede interna mais clara e menos áspera.

${ }^{4}$ Estes grafitos, que devem ter sido utilizados para controle da produção, foram gravados com estilete na pasta ainda húmida e com as ânforas apoiadas sobre a boca. Não é caso único para os fornos do Vale da Cepa, antes comum aos outros fornos do Sado: nos fornos da Marateca foi utilizado um «P» (F. DE ALMEIDA et aíii, Marateca, est. VII), no forno $1 \mathrm{da}$ Barrosinha um «B» (inédito, mas observável num bico fundeiro aparecido no Castro de Fiães - C. de Almeida e E. dos Santos, Fiães, est. VI, n. ${ }^{\circ}$ 5) e ainda no forno 4 do Bugio (inédito).

Conimbriga, 22 (1983), 209-215 
6. Fragmento de bordo e colo de ânfora DRESSEL 14. Lábio espesso e perolado. Reentrância para o opérculo pouco pronunciada. Diâmetro interno da boca: $15 \mathrm{~cm}$.

Pasta amarelo-alaranjada, cerne pequeno de tonalidade laranja-avermelhado. Engobe ligeiramente mais escuro do que a pasta. Parede interna menos áspera e mais clara.

7. Bico fundeiro de DRESSEL 14, terminado em glande. Pasta amarelo-alaranjada, cerne laranja-avermelhado. Engobe de tonalidade amarelo-acastanhado em superfície bem alisada. Parede interna sem engobe.

8. Bico fundeiro de DRESSEL 14, de base côncava. Grafito em forma de cruz $(2,4 \mathrm{~cm}$ de altura por $1,5 \mathrm{~cm}$ de largura. Gravado com estilete na pasta, húmida, com a ânfora apoiada sobre a boca. Foi primeiramente feito o corte vertical, com o sentido de cima para baixo e depois o horizontal com o sentido da esquerda para a direita).

Pasta amarelo-alaranjado, cerne laranja-avermelhado. Engobe acastanhado sobre a superfície exterior, bem alisada.

9. Fragmento de boca, colo e asa de ânfora ALMAGRO 51C. Lábio de secção triangular, revirado para fora e boleado do lado externo. Uma pequena canelura separa o bordo do colo. Pronunciado estrangulamento interior para encaixe do opérculo. Asas de secção rectangular, arrancando do meio do lado externo do lábio. Diâmetro interior da boca: $8 \mathrm{~cm}$. Pasta de tonalidade uniforme, amarelo-acinzentado. Engobe creme-acastanhado em superfície bem alisada.

10. Fragmento de boca, colo e arranque de asa de ânfora ALMAGRO 51C. Lábio de secção oval, revirado para fora e duplamente boleado. Asa arrancando do exterior do lábio. Diâmetro interno da boca: $11,2 \mathrm{~cm}$. Pasta amarelo-alaranjado; cerne muito extenso, mais alaranjado. Engobe castanho-acinzentado em superfície bem alisada.

11. Fragmento de boca, colo e arranque de asa de ânfora ALMAGRO 51C. Lábio de secção triangular, revirado para fora e boleado do lado externo. Pequena depressão no lado externo do lábio. Arranque da asa no terço inferior do lábio. Diâmetro interior da boca: 10,2 em, Pasta ocre-acinzentada, cinzenta no cerne. Engobe alterado.

12. Bico fundeiro de ânfora ALMAGRO 51G. Curto de secção tronco-cónica. Base ligeiramente côncava. Maior largura $11,5 \mathrm{~cm}$, altura $8 \mathrm{~cm}$; relação altura/largura 1,4:1.

Pasta de tonalidade uniforme, creme-alaranjado. Vestígio de engobe na parede exterior, de tonalidade cinzento-azulada sobre parede alisada, com muitas estrias horizontais. 


\section{BIBLIOGRAFIA}

Alarcão, Jorge de - Cerâmica comum local e regional de Conimbriga, Coimbra, 1974.

«Les Amphores», in Fouilles de Conimbriga, VI, Paris, 1976.

Almeida, Carlos A. F. de e Santos, Eugénio dos - O Castro de Fiäes, «Revista da Faculdade de Letras — Série de Historia», II, Porto, 1971, p. 147-168.

Almeida, D. Fernando de, Zbyszemsis, G. e Ferreira, O. da Veiga, Descoberta de fornos lusitano-romanos na região da Mar ateca (Setúbal), «O Arqueólogo Português», Série III, vol. V, Lisboa, 1971, p. 155-165.

BAptista, Joaquim Correia - Salada, «O Archeologo Português», vol. II, n. ${ }^{\circ} 1$, Lisboa, 1896, p. 5-10.

BELT RÁN LLORIS, M. - Las ánforas romanas en España, Zaragoza, 1970.

CARDoso, Guilherme - Anforas romanas no Museu do Mar (Cascais), «Conimbriga», XVII, Coimbra, 1978, p. 63-78.

Diogo, A. M. Dias - Fornos de ânforas do Monte do Bugio. Notícia preliminar, «Conimbriga», XIX, Coimbra, 1980, p. 147-150.

PARKER, Antony J. - Lusitanian Amphoras, in Méthodes Classiques et Méthodes Formelles dans VÉtude des Amphores, Roma, 1977, p. 35-46.

R A U, Virginia - A exploração e o comércio do sal de Setúbal, Lisboa, 1951 


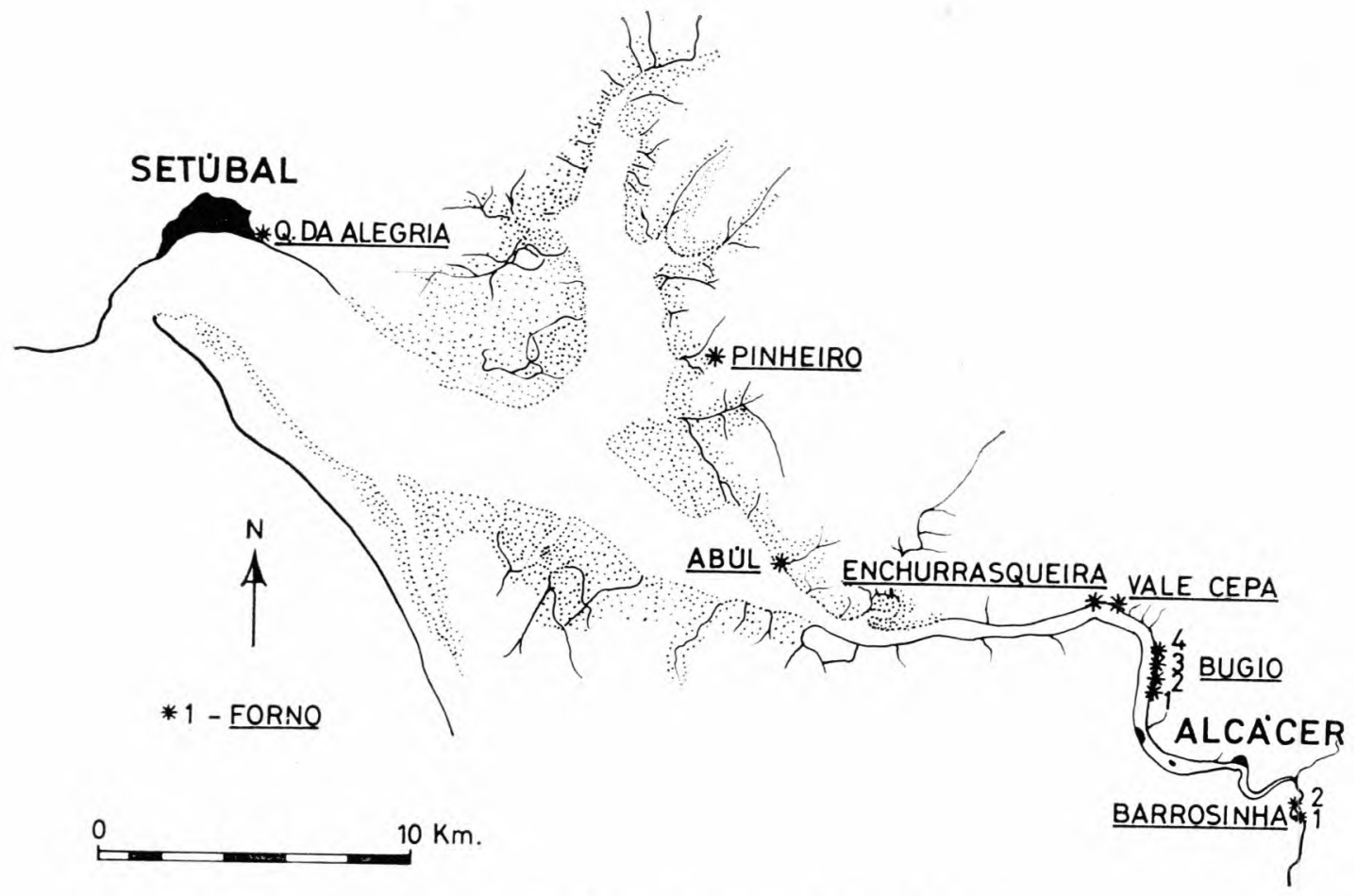

Localização de alguns fornos no curso inferior do Sado 


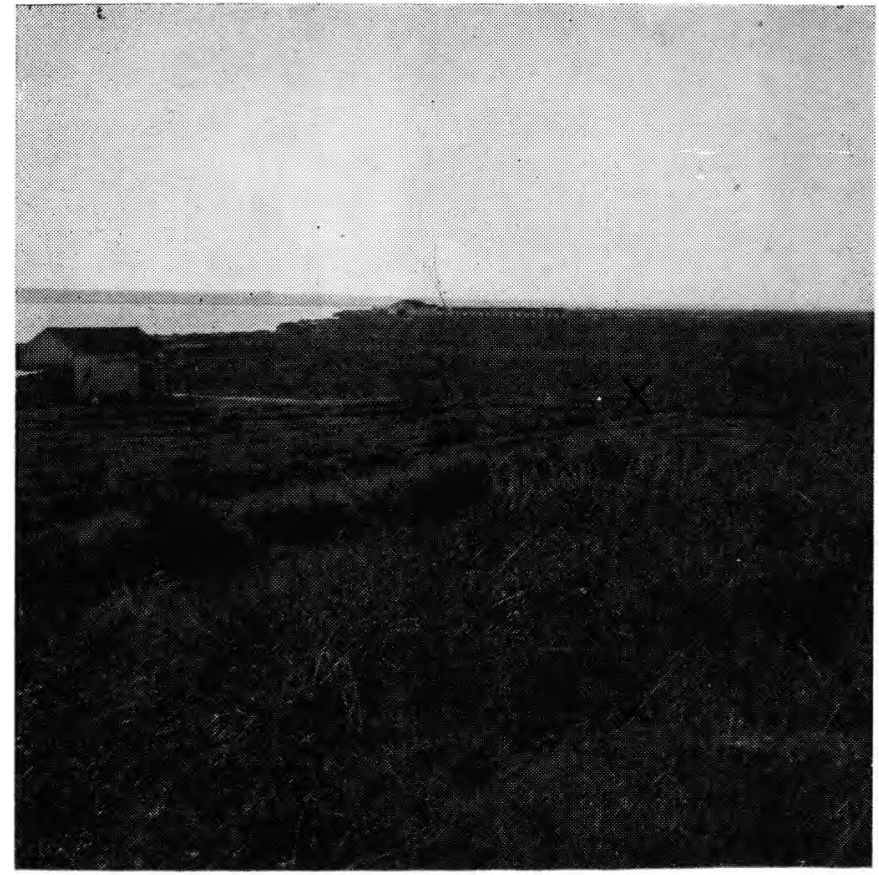

Monte da Enchurrasqueira visto de Este. O x marca o local de onde sairam os materiais aqui publicados. 
III
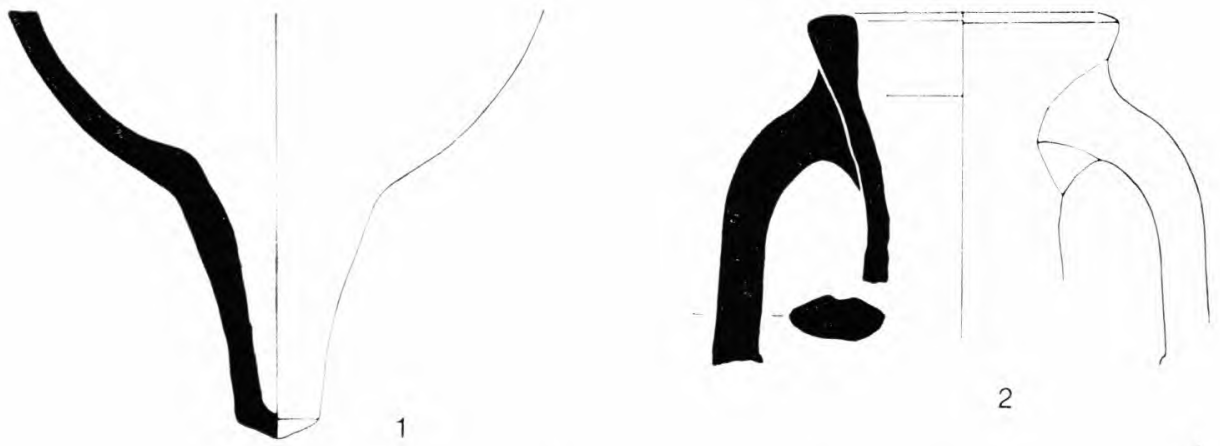

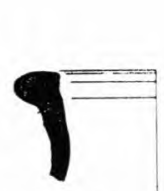

3

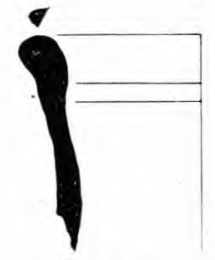

6
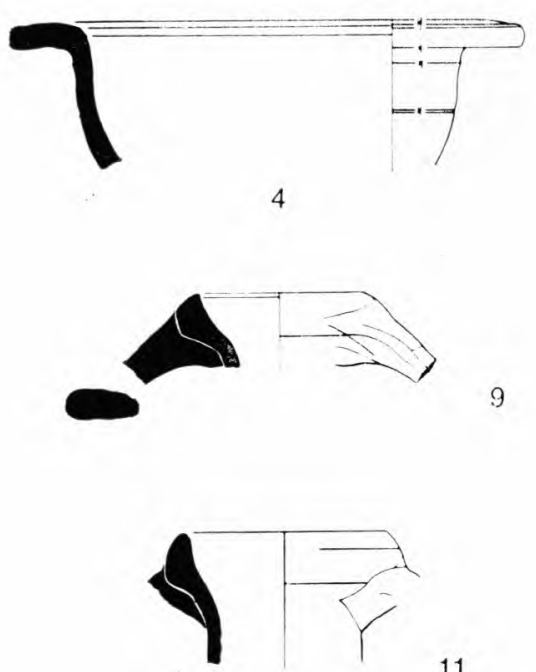
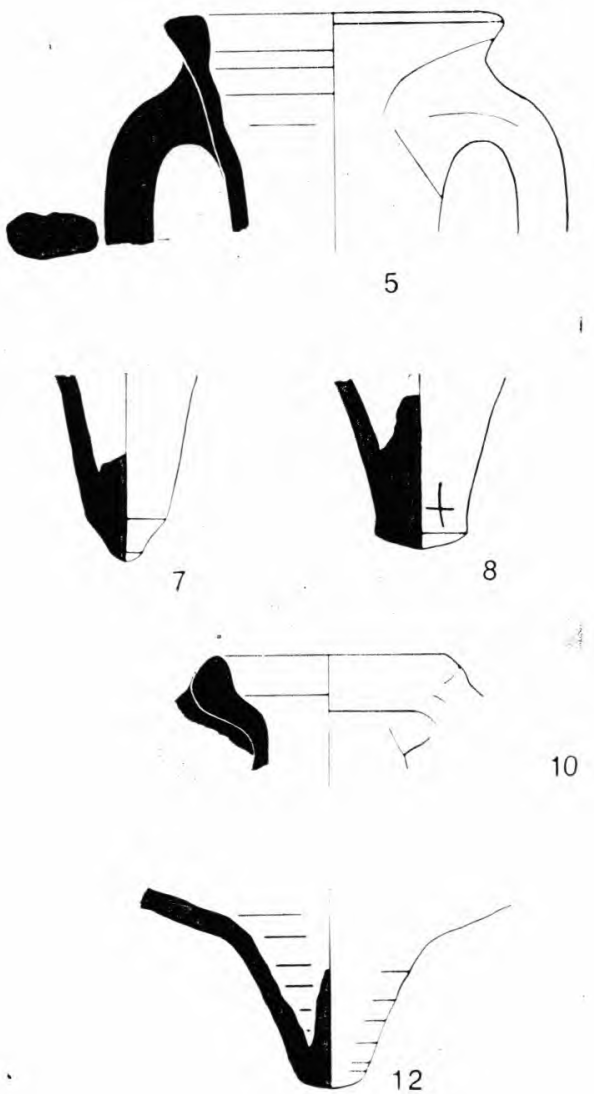